\title{
- Early Language Development in Children with a Genetic Risk of Dyslexia
}

\author{
Petra van Alphen, Elise de Bree, Ellen Gerrits, Jan de Jong, \\ Carien Wilsenach and Frank Wijnen* \\ Utrecht Institute of Linguistics OTS, Utrecht University, Netherlands
}

We report on a prospective longitudinal research programme exploring the connection between language acquisition deficits and dyslexia. The language development profile of children at-risk for dyslexia is compared to that of age-matched controls as well as of children who have been diagnosed with specific language impairment (SLI). The experiments described concern the perception and production of grammatical morphology, categorical perception of speech sounds, phonological processing (non-word repetition), mispronunciation detection, and rhyme detection. The results of each of these indicate that the at-risk children as a group underperform in comparison to the controls, and that, in most cases, they approach the SLI group. It can be concluded that dyslexia most likely has precursors in language development, also in domains other than those traditionally considered conditional for the acquisition of literacy skills. The dyslexia-SLI connection awaits further, particularly qualitative, analyses. Copyright (C) 2004 John Wiley \& Sons, Ltd.

\footnotetext{
Keywords: at-risk populations; language disorders; reading disabilities; morphology; grammar; phonology
}

\section{INTRODUCTION}

$\mathrm{P}$ revious studies have found that developmental dyslexia ${ }^{\star}$ and language acquisition deficiencies are related (Catts, Fey, Zhang, \& Tomblin, 2001; Gallagher, Frith, \& Snowling, 2000; Scarborough, 1991). The research project reported on here was designed to explore this relationship in more detail, by using a prospective and longitudinal approach. The principal aim is to determine whether children with a genetic risk for dyslexia show a delayed or

*Correspondence to: Frank Wijen, UIL OTS, Trans 10, 3512 JK Utrecht, Netherlands. Tel.: +31-30-253-6436; fax: +31-30-253-6000; e-mail: frank.wijnen@let.uu.nl

*Dyslexia is defined as an inability to attain fluent reading and writing skills in the absence of general cognitive, neurological or sensory deficits, inadequate education, unfavourable social conditions, etcetera (cf. the World Federation of Neurology criteria). 
deviant primary language acquisition in comparison to age-matched children from families without a history of dyslexia. The children were assessed on a wide range of linguistic abilities, including phonological, morphological, lexical and syntactic skills. The results from these measures might contribute to the search for early linguistic precursors of dyslexia. Furthermore, in order to improve our understanding of the linguistic difficulties that the at-risk children exhibit, their language development was compared to those of children with specific language impairment (SLI). Thus, inclusion of children with SLI provides a 'benchmark' of non-typical language acquisition. The comparison between the at-risk and SLI children also adds to the current discussion in the literature that dyslexia and SLI are closely related (Catts, 1993; Catts \& Kamhi, 1999; MacArthur, Hogben, Edwards, Heath, \& Mengler, 2000).

A number of prospective studies have looked at the connection between language acquisition and dyslexia. Scarborough (1990, 1991) conducted a pioneering study with children at-risk for developing dyslexia. Sixty-five percent of the children in her sample were classified as dyslexic by the age of 8 years. At age 30 months, these children demonstrated a more restricted range of syntactic devices and made more speech production errors. At the ages of 36 and 42 months, the vocabulary skills of the dyslexic children were less well developed than those of the controls and their syntactic difficulties persisted. Scarborough claimed that phonological awareness skills did not account for significant variance in reading outcome, but that syntactic skills constituted a unique predictor of reading disability.

Despite Scarborough's finding, the majority of more recent studies with children at-risk for dyslexia focussed on the areas of phonology, speech perception and verbal short memory. For example, Locke et al. (1997), Pennington and Lefly (2001), Lefly and Pennington (1996) and Byrne, Fielding-Barnsley, Ashley, and Larsen (1997) found that the strongest predictors of dyslexia are deficiencies in the areas of phonological processing and metaphonological ability. However, a few recent studies did investigate the syntactic proficiency of at-risk children. Gallagher et al. (2000) found (consistent with Scarborough) that preschool syntactic ability was a significant predictor of reading at 8 years. Lyytinen, Poikkeus, Laakso, Eklund, and Lyytinen (2001) reported that maximum sentence length at age two and object naming and inflectional morphology skills at 3;6 years were less well developed in a group of at-risk children compared to normal controls.

Summarising, many prospective studies indicate that at-risk children display deficiencies in speech perception, phonological processing, verbal short-term memory and metaphonological abilities. The pattern with regard to productive phonology, the reception and production of morphology and of syntax is much less clear. Our study overlaps in part with those reviewed above, but is complementary in part as well. In addition to some of the widely applied measures of speech perception skill, phonological processing and short-term memory, we have included fine-grained assessments of primary

\footnotetext{
"SLI is defined as a delay in language acquisition in the absence of demonstrable perceptual or neurological deficits, low (non-verbal) intelligence, or sub-optimal socioemotional conditions (Leonard, 1998).
} 
phonological, morphological, lexical and syntactic skills, both in production and reception.

The current study differs from previous prospective studies in that we compared our at-risk children not only to 'non-risk' controls, but also to children with SLI. The primary symptoms of SLI are most prominent in language production. Typically, children with SLI display problems with the acquisition of morphology and sentence structure (Fletcher \& Ingham, 1995). These grammatical problems are often accompanied by phonological shortcomings. Forty to $50 \%$ of the children diagnosed with SLI experience difficulties in learning to read (Leonard, 1998). Conversely, the majority of children diagnosed with dyslexia appear to have had difficulties in language development during the preschool years (Catts, 1993). Furthermore, the language (processing) symptoms observed in children with dyslexia are by and large the same as those in children with SLI (Kamhi \& Catts, 1986). Both groups have been found to show deficits in speech perception, phonological awareness, repeating words and sentences, grammaticality judgment and rapid naming. The phenotypical similarity between dyslexia and SLI is demonstrated by MacArthur et al. (2000), in which a blind re-evaluation procedure revealed that about $50 \%$ of both dyslexic children and children with SLI fulfilled the criteria of the alternative diagnostic category.

One way to account for both the strong correlation between language acquisition difficulties and dyslexia, as well as the overlap in symptoms, is to say that dyslexia stems from a language disorder. Catts and Kamhi (1999) present this point of view, and argue that dyslexia is the outcome of a deficit in phonological processing (see Snowling, 2001), i.e. the perception, encoding, retrieval and use of phonological forms. However, as Scarborough's results (1990) suggest, other aspects of linguistic competence, notably syntax, may also be compromised in dyslexic children. Our aim is therefore not only to investigate phonological abilities, but various linguistic skills in both at-risk and SLI children.

The children we study are between 18 and 60 months of age. The at-risk children, born from 'dyslexic families', have been estimated to have a 40-60\% chance of becoming dyslexic, as compared to approximately $4 \%$ in the population at large (Grigorenko, 2001). Since the children have not been exposed to formal education in reading and spelling at the time of testing, it is not possible to determine who among them are dyslexic. Nevertheless, we anticipate that a considerable number of children in the at-risk group will display difficulties on the language tasks. Therefore, we expect that the at-risk group as a whole will display a level of performance in between that of the normally developing children and of the SLI children.

Each of the experiments presented here focus on either morphology/syntax or on phonetics/phonology. The morphology/syntax component includes a study of the perceptual sensitivity to grammatical patterns, and an analysis of elicited production of nominal and verbal inflections. The phonetics/phonology component comprises experiments on categorical perception, phonological processing, mispronunciation detection (word recognition) and rhyme detection. The tasks were presented to the children at different ages, as indicated in Table 1. Each task can be considered constitute a separate experiment, and is presented as such below. However, each experiment involved participants from the same pool 
Table 1. An overview of the experiments

\begin{tabular}{ll}
\hline Age & Experiment \\
\hline 19 months & 1A: sensitivity to grammatical patterns: preferential listening \\
25 months & 1B: sensitivity to grammatical patterns: preferential listening \\
$3 ; 3-3 ; 7$ & 2: production of grammatical morphology \\
$3 ; 11-4 ; 4$ & 3: categorical perception of speech sounds \\
$4 ; 5-4 ; 8$ & 4: phonological processing (non-word repetition) \\
$5 ; 1-5 ; 4$ & 5: mispronunciation detection \\
$5 ; 1-5 ; 4$ & 6: rhyme detection \\
\hline
\end{tabular}

(consisting of two cohorts, see below). Therefore, we first give a description of our participants, followed by a sketch outline the general procedures followed in our project.

\section{PARTICIPANTS}

Approximately 250 children took part in the project. These children can be divided in two age cohorts, labelled 'infants' and 'toddlers', referring to the age at which the participants joined the project. The infant cohort consists of about 70 at-risk children and 40 controls. These children were between the ages of 18 to 22 months when they entered the programme. The toddler cohort comprises about 70 at-risk children, 40 controls and 30 children with SLI, each of them between age 3;0 (years; months) and 3;6 at entrance. SLI children were not included in the infant cohort, because SLI cannot be diagnosed reliably at that age (e.g. Paul, 2000).

The at-risk children were recruited through an advertisement campaign. For children to be included in the at-risk group, at least one parent had to be classified as dyslexic. Following the procedure described in Koster et al. (2004), the dyslexic parent was tested on a number of standardised measures: a single word reading test (One-minute-test, Brus \& Voeten, 1973), a pseudo-word reading test (Van den Bos, Lutje Spelberg, Scheepstra, \& de Vries, 1994), a pseudo-word dictation, a non-word repetition task, as well as a rapid naming task. The verbal comprehension test from the Wechsler Adult Intelligence Scale was also administered. A parent was classified as dyslexic if either of the two word reading test scores were in the bottom $10 \%$ range, or if both were in the lower 25\% range. A strong discrepancy between the score on the pseudo-word reading test and the verbal comprehension test $(\geqslant 60 \%)$ also resulted in a dyslexic classification. In view of the reported overlap between dyslexia and language impairment, we enquired about speech-language problems in the families of the at-risk children. Generally, the parents did not report having had any clinically significant problems in this area. Unfortunately, no Dutch language test that allows testing of language-impaired adults exists. Assessing whether the dyslexic parents in our sample might have been language-impaired as children therefore remains difficult. ${ }^{\S}$

\footnotetext{
${ }^{\S}$ Some researchers (e.g. Catts et al., 2001) have used the non-word repetition task to distinguish between adults with and without a language impairment, but this test is also administered to distinguish between adults with and without dyslexia.
} 
The control children, age-matched with the at-risk children, were recruited via day-care centres. We ascertained that no history of dyslexia and speech-language difficulties occurred in the families of these children.

Children in the SLI-group were recruited from schools providing full-time specialised teaching to children suffering from language and speech problems. These children had been classified as language-impaired after extensive assessment by a speech/language pathologist or a clinical linguist, which comprised assessment of their speech and language skills, nonverbal cognitive abilities, and hearing. Exclusion criteria that are commonly adopted when children with SLI are selected for research were used here as well: no primary perceptual disorder or known neurological deficit should be attested, and intelligence should be within normal range. These criteria also answer the admission criteria for the schools for language-impaired children. For our purpose, two exclusion criteria were added: signs of autism-spectrum disorders and signs of verbal dyspraxia.

Table 2 presents an overview of some of the relevant individual and demographical characteristics of the participant groups. We looked at IQ (as measured by a Dutch standardised test (SON-R, Snijders, Tellegen, \& Laros, 1988), birth rank order and educational level of the mother. It should be kept in mind that these data are not complete as yet (cf. 'number tested' in Table 2). Nonetheless, we believe that the table provides a reliable characterisation of our samples.

The educational level of the mother was classified in accordance with number of years in secondary school (and school type, but these are correlated). Level 1 represents 4 years of secondary school, Level 2, 5 years, Level 3, 6 years (comprising either advanced vocational training or preparatory training for university), Level 4, 8 years and more, comprising tertiary education at BA up to MA level. It is clear from Table 1 that all mothers belong to the higher categories. There is no significant difference in education level between the three groups of

Table 2. Overview of some demographical and individual characteristics of the participants. Mother's education level: $1=4$ years of secondary education; $2=5$ years; $3=6$ years; $4=$ tertiary education up to BA/MA

\begin{tabular}{|c|c|c|c|c|c|c|}
\hline & \multicolumn{2}{|c|}{ Mother's education } & \multicolumn{2}{|c|}{ IQ (SON-R) } & \multicolumn{2}{|c|}{ Birth order } \\
\hline & $\begin{array}{l}\text { Mean } \\
\text { (s.d.) }\end{array}$ & $N$ tested & $\begin{array}{l}\text { Mean } \\
\text { (s.d.) }\end{array}$ & $N$ tested & $\begin{array}{l}\text { Mean } \\
\text { (s.d.) }\end{array}$ & $N$ tested \\
\hline \multicolumn{7}{|l|}{ Baby cohort } \\
\hline Control & $\begin{array}{l}3.6 \\
(0.55)\end{array}$ & 35 & $\begin{array}{l}110.7 \\
(17.3)\end{array}$ & 31 & $\begin{array}{c}1.5 \\
(0.70)\end{array}$ & 36 \\
\hline At-risk & $\begin{array}{l}3.2 \\
(0.91)\end{array}$ & 66 & $\begin{array}{c}108.5 \\
(15.0)\end{array}$ & 63 & $\begin{array}{c}1.7 \\
(0.83)\end{array}$ & 60 \\
\hline \multicolumn{7}{|l|}{ Toddler cohort } \\
\hline Control & $\begin{array}{l}3.7 \\
(0.77)\end{array}$ & 18 & $\begin{array}{l}115.2 \\
(15.6)\end{array}$ & 30 & $\begin{array}{c}1.2 \\
(0.67)\end{array}$ & 12 \\
\hline At-risk & $\begin{array}{c}3.1 \\
(1.2)\end{array}$ & 53 & $\begin{array}{l}111.3 \\
(14.4)\end{array}$ & 61 & $\begin{array}{c}1.3 \\
(0.59)\end{array}$ & 41 \\
\hline SLI & $\begin{array}{c}3.3 \\
(1.3)\end{array}$ & 9 & $\begin{array}{c}101.9 \\
(10.1)\end{array}$ & 22 & $\begin{array}{c}2.4 \\
(1.1)\end{array}$ & 9 \\
\hline
\end{tabular}


mothers in the toddler cohort. In the infant cohort, the control children's mother's educational careers have been slightly but significantly longer than those of the at-risk children's mothers $(F(1,99)=4.92, p=0.029$, one-way ANOVA).

Table 2 further indicates that the children in all groups fall within the normal IQ range. No statistically reliable difference was found between average IQs of the control and at-risk infants. In the toddler cohort, the three groups' average scores differ significantly in a one-way $\operatorname{ANOVA}(F(2,110)=5.93, p=0.004)$. Post hoc tests indicate that the SLI group differs from both the controls and the at-risk children.

Regarding birth rank, the one interesting observation is that the average for SLI children is considerably higher than that of the other two toddler groups, resulting in a significant effect $(F(2,59)=12.53, p=0.004$, one-way ANOVA). This is consistent with previous results showing that laterborn children have higher rates of language problems (Bishop, 1997; Tomblin, 1989).

\section{GENERAL PROCEDURE}

All children were invited to take part in four test sessions, separated by 6-month intervals. Consequently, the children in the infant cohort, who were first seen at $1 ; 6$, were $3 ; 0$ or slightly older at the time of the final session. This is roughly the same age as the children from the toddler cohort at their first time of testing. The toddlers were approximately 5;0 in the last test session.

The sessions took place either in the language acquisition lab at the Utrecht institute of Linguistics OTS (for most at-risk children and controls), or in children's schools or homes (for most SLI children). Each test session consisted of a number of age-appropriate and tailor-made tasks, allowing us to address specific questions, probing both perceptive and productive language skills. Procedural details will be given below. In addition, all children were administered a standardised IQ test (see above), as well as an adaptation of the digit span test from the WISC.

In this paper, we report on a subset of experiments within the programme (see Table 1). All children in one age-cohort participated in all experiments assigned to their cohort. This means that the participant groups of the various experiments overlap. Note, however, that the results presented here may refer to subsets of participants, due to subject drop-out (as reported where appropriate below), or because the analyses of the results have not been completed as yet.

\section{EXPERIMENT 1: SENSITIVITY TO GRAMMATICAL PATTERNS}

In dyslexia, (meta)phonological deficits have long been recognized as critical. Much less is known about the syntactic abilities of children with dyslexia. One prerequisite for the acquisition of grammar is the capacity to recognise grammatical patterns in the ambient language. These grammatical patterns are also referred to as 'grammatical dependencies', since the presence of one morpheme in the pattern is dependent on the presence of another. Previous studies (Höhle \& Weissenborn, 2003; Santelmann \& Jusczyk, 1998) have shown that normally developing children aged 18 months are sensitive to the occurrence 
of grammatical dependencies in their mother tongue. We assessed the at-risk infants' ability to recognise one specific grammatical dependency in Dutch by using the preferential listening task. The preferential listening task measures the time children listen to passages of continuous speech. The passages are usually divided into two types, in this case into grammatical and ungrammatical passages. A listening preference to either of the types of passages indicates that children discriminate between the different passages. Although it is theoretically not possible to predict the direction of children's preferences, previous studies generally found a familiarity effect (i.e. a preference for familiar/grammatical materials (e.g. Santelmann \& Jusczyk, 1998). The present experiment focused on the dependency between the temporal auxiliary heeft ('has') and the past participle. We tested whether children were able to discriminate this from a distorted dependency, in which heeft is replaced by the modal auxiliary kan 'can'. If children are sensitive to this particular dependency, we expect them to prefer the passages in which the dependency is maintained. The absence of a clear preference, however, would imply a reduced sensitivity to the dependency between heeft and the past participle.

\section{Participants}

Two preferential listening experiments have been conducted, involving the same procedure and materials. In the first experiment (1A), 79 at-risk children took part, as well as 39 control children. The data of 22 at-risk and nine control children had to be excluded for various reasons. The average age of both the atrisk and control infants was 19.7 months. In the second experiment (1B), we analysed the results of 54 at-risk children, who had already participated in experiment 1 . The data of an additional 13 children were excluded for various reasons. The children had an average age of 25.6 months.

\section{Materials and Procedure}

The stimuli consisted of 16 spoken passages. Eight of these contained fully grammatical sentences each containing a grammatical combination of the temporal auxiliary heeft 'has' and a past participle, as in example 1. The past participle is marked by the prefix ge- [xə]. The other eight consisted of sentences with an ungrammatical combination of the modal auxiliary kan 'can' and a past participle (example 2). The auxiliary and past participle were always separated by a two-syllable adverb. The ungrammatical passages exactly matched the grammatical passages except for the auxiliaries. All comprised eight sentences, and were 77 or 78 syllables long. Through editing, the duration of the passages was set to a constant 20.9 s.

(1) De boer heeft gewerkt. (The farmer has worked).

(2) *De boer kan gewerkt. (The farmer can worked).

The experiments were conducted in a soundproof booth, in which the stimuli were presented randomly through either of two speakers, situated to the children's right and left hand sides. At the beginning of each trial, the child's attention was drawn to the centre by flashing a green light. When the child 
looked at this centre light, it stopped flashing while a red light on one of the side panels started flashing, indicating the availability of an auditory stimulus on that side. Once the participant made a head turn of at least $30^{\circ}$ to that side, the speech stimulus began to play. The speech stimulus and flashing light continued until the child turned away for a continuous period of 2 seconds or until the entire stimulus had been played. Listening time was calculated by adding up the total time the child was orientated to the speech sample. Each run of the experiment comprised four training trials and 12 test trials.

\section{Results and Discussion}

Mean listening times across all subjects in the control group were calculated for both the grammatical and the ungrammatical passages. In experiment 1A, (see Figure 1, upper panel) the mean listening time to the grammatical passages was 9.61 seconds $(\mathrm{SE}=0.70$ ) whereas the mean listening time to the ungrammatical passages was 8.21 seconds $(\mathrm{SE}=0.73)$. The difference is significant in a paired samples $t$-test $[t(29)=2.21, p=0.035] .67 \%$ of the infants in the control group (i.e. 20 of the 30 subjects) preferred (i.e. listened longer to) the grammatical passages. The mean listening times across all children in the at-risk group were 8.0 seconds ( $\mathrm{SE}=0.46$ ) for the grammatical passages and 8.69 seconds $(\mathrm{SE}=0.49$ ) for the ungrammatical passages. A paired $t$-test indicated that the difference is not significant: $t(56)=-1.8, p=0.077$. Only $46 \%$ of the at-risk infants (i.e. 26 of the 57 subjects) listened longer to the grammatical passages.

In experiment 1B (Figure 1, lower panel), the at-risk children listened to the grammatical passages for 8.56 seconds on average $(\mathrm{SE}=0.46)$, while their mean listening time to the ungrammatical passages was 8.83 seconds $(\mathrm{SE}=0.49$ ). A paired samples $t$-test indicated that the 0.27 -s difference is not significant $[t$ $(52)=-0.423, P=0.47$ ]. Further inspection of the data revealed that $46 \%$ of the subjects listened longer to the grammatical passages and $54 \%$ listened longer to the ungrammatical passages. This result is identical to the result in experiment $1 \mathrm{~A}$.

Taken together, the results of experiment $1 \mathrm{~A}$ and $1 \mathrm{~B}$ imply that the control infants are sensitive to the co-occurrence of the temporal auxiliary and the past participle. The control children are able to discriminate between grammatical and ungrammatical dependencies at the age of 19 months. The at-risk children showed no significant preference for either the grammatical or the ungrammatical passages, neither in experiment $1 \mathrm{~A}$ nor experiment $1 \mathrm{~B}$, indicating that they were unable to discriminate between the grammatical and the ungrammatical passages. This implies that the at-risk infants failed to recognise the grammatical dependency between the auxiliary heeft and the past participle at the age of 19 months. Furthermore at the age of 25 months, the at-risk children showed no evidence of catching up with the control children. This suggests that the development of the at-risk children's perceptual language skills is delayed by (at least) six months.

The inability of the at-risk children to track relationships between morphemes might have a negative effect on the development of language production in these children. It might be that the perceptual delay results in these children being less equipped for structuring and decoding longer, more complex sentences. It is 


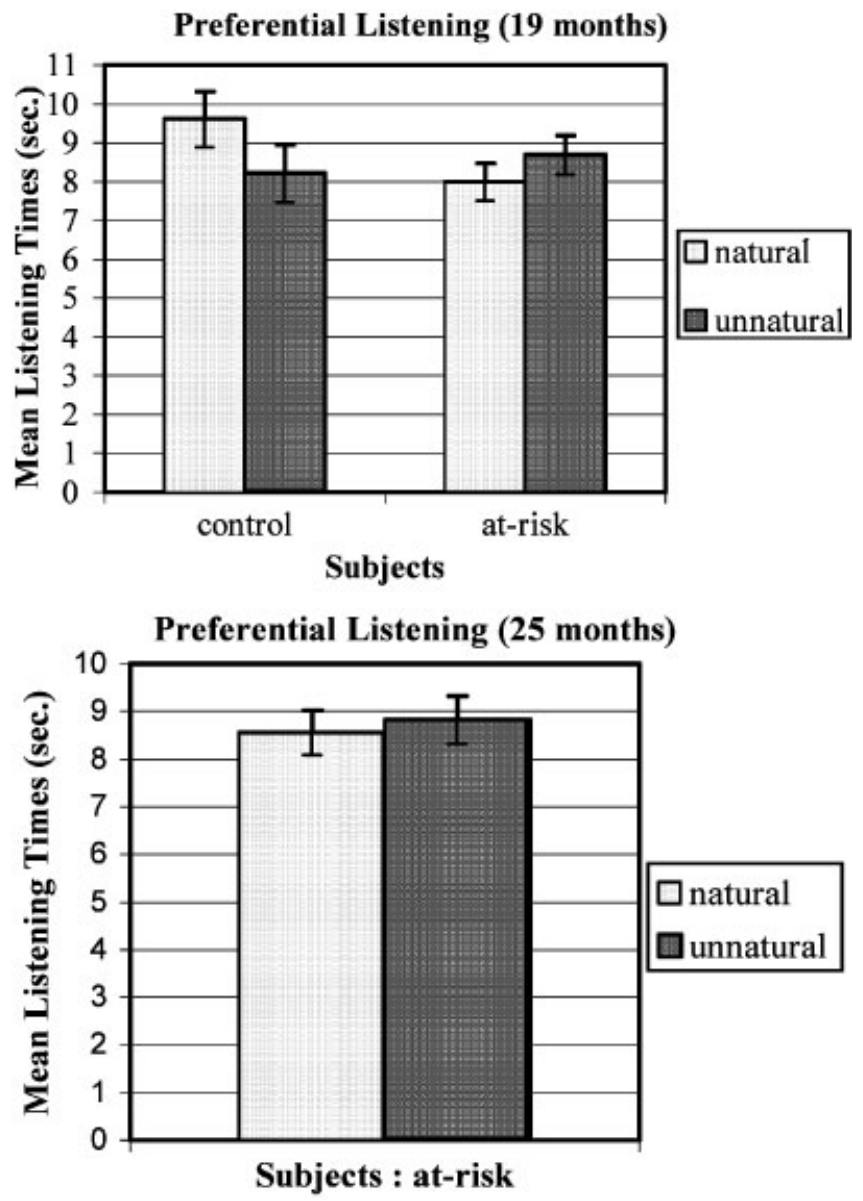

Figure 1. Preferential listening: mean average listening times to grammatical and ungrammatical passages by at-risk children and controls, 19 months of age (upper panel); at-risk children at 25 months (lower panel).

therefore likely that the at-risk children will start producing this particular grammatical dependency at a later stage than the control children.

\section{EXPERIMENT 2: PRODUCTION OF GRAMMATICAL MORPHOLOGY}

For children with SLI, inflection usually is a major hurdle. This is true for nominal as well as verbal marking, although verbal inflection is generally more strongly affected than nominal morphology (Bishop, 1994; Oetting \& Rice, 1993). The difficulties with morphology are expected to be mirrored in the language output of children at-risk for dyslexia. To test this, we ran an elicited production task, designed to test children's knowledge of plural formation in the nominal domain and third person singular agreement in the verbal domain. 


\section{Participants}

The verb inflection task was completed by 35 at-risk children (average 3;3), nine children with SLI $(3 ; 7)$ and 27 controls $(3 ; 3)$, all from the toddler cohort. The noun-plural task was completed by 37 at-risk children, 10 children with SLI and 27 controls, their average ages being the same as for the sample in the verb inflection task. The number of children participating was different across the tasks, due to the fact that not every child completed each task.

\section{Materials and Procedure}

The format of the elicitation task was that of a standard grammatical closure task (cf. ITPA-GC, Kirk, McCarthy, \& Kirk, 1968). The child was shown two pictures. The first picture was described by the experimenter, while in the description of the second picture the final constituent was omitted, inviting the child to complete the sentence. In the pluralisation conditions, the first picture contained a single exemplar of a referent to be named (e.g. a ball); the second picture contained multiple referents. In this case, the experimenter would enounce Dit is een bal en dit zijn twee...? (This is a ball and these are two ...?). The numeral twee ('two') was stressed here. The noun plural task comprised 10 such items presented in a fixed order.

In the verb agreement task, pictures of an animate figure (a bear) performing different actions were shown. The experimenter described the first action, using a full subject-predicate construction. The child was invited to complete the description of the action in the second picture, e.g. Deze beer loopt en deze beer...? (This bear walks and this bear...?). The introduction of the subject in the second prompt, paired with the inflected verb in the first prompt, was expected to encourage the use of a finite lexical verb. This is important, given that in the initial stages of verb use children often opt for bare infinitives (i.e. verbs without a proper inflectional morpheme). It should be noted that, unlike English, Dutch has an infinitive marker, $-e n$. An infinitival verb in an independent sentence must be connected to an (inflected) auxiliary. Dutch children's acquisition of this constraint is often reflected by an increase in the use of the semantically empty auxiliary gaan (go) (Wijnen \& Verrips, 1998). The task consisted of 10 items presented in a fixed order.

\section{Results and Discussion}

Table 3 shows the results of the pluralisation task. The at-risk children produce fewer correct plurals than the controls, and the children with SLI in their turn

Table 3. Grammatical morphology. Average numbers of responses (standard deviations in parentheses) in the elicited production task, pluralisation conditions, for each of the three groups of children

\begin{tabular}{llll}
\hline & & Response & \\
\cline { 2 - 4 } Group & Plural & Singular & None \\
\hline Control & $8.96(1.22)$ & $0.78(0.97)$ & $0.26(0.52)$ \\
At-risk & $6.65(2.85)$ & $1.70(1.79)$ & $1.65(1.99)$ \\
SLI & $5.80(3.23)$ & $2.60(2.67)$ & $1.60(2.41)$ \\
\hline
\end{tabular}


Table 4. Grammatical morphology. Average numbers of responses (standard deviations in parentheses) collected in the elicited production task, verbal inflection conditions, for each of the three groups of children

\begin{tabular}{lccccc}
\hline & \multicolumn{5}{c}{ Response type } \\
\cline { 2 - 6 } Group & 3rd sing. & Stem & Infinitive & aux+ inf. & No verb \\
\hline Control & 4.00 & 0.30 & 1.63 & 2.70 & 1.37 \\
& $(3.43)$ & $(0.82)$ & $(2.07)$ & $(2.98)$ & $(1.49)$ \\
At-risk & 3.06 & 1.00 & 2.51 & 1.33 & 1.60 \\
& $(3.09)$ & $(1.13)$ & $(2.29)$ & $(2.59)$ & $(1.26)$ \\
SLI & 1.44 & 0.66 & 4.33 & 1.33 & 2.44 \\
& $(2.46)$ & $(0.72)$ & $(2.95)$ & $(2.69)$ & $(2.13)$ \\
\hline
\end{tabular}

produce fewer than the at-risk children. The effect of participant group on average number of correct plurals is statistically reliable in a oneway ANOVA $(F(2,71)=9.39, p<0.001)$. Post hoc Tukey HSD tests indicate significant differences ( $p=0.002$ and less) between the control group and both the at-risk children and children with SLI. The difference in number of correctly produced plural forms between the latter two groups does not reach significance.

The results of the inflection task are presented in Table 4. With regard to the average number of third person singular (3SG) forms, the effect of group is not reliable in a one-way ANOVA $(F(2,68)=2.29, p=0.109)$. However, when we take all-grammatical - finite forms into account, i.e. 3SG as well as combinations of a finite auxiliary (most often gaan) and an infinitive main verb, the effect of group is significant $(F(2,68)=8.77, p<0.001)$. Furthermore, as to the incorrect responses (ungrammatical forms), it appears that the response profiles of the three groups are different. At-risks seem to produce more stem forms, whereas children with SLI seem to prefer bare infinitives. This is confirmed by the results of a multivariate ANOVA, with the numbers of stems, infinitives and non-verb responses as dependent variables. We see an overall significant effect of group on the incorrect response pattern $(F(6,134)=3.18, p=0.006)$. Tests for the separate dependent variables show an effect on stem forms $(F(2,68)=4.15, p=0.02)$, and infinitives $(F(2,68)=4.72, p=0.012)$. Tukey HSD post hoc tests yield a significant difference between the control group and the at-risk group with regard to number of stem forms ( $p=0.018)$, as well as a significant difference between the control group and the SLI group with regard to the number of infinitives $(p=0.009)$.

In summary, these results clearly indicate that the at-risk and SLI groups produce fewer correct forms (and more often fail to respond) both in the verbal inflection conditions and in the nominal plural conditions. The performance of the at-risk children is positioned in-between that of the controls and the SLI children. Taken together, the results of this experiment confirm that children with a genetic risk for dyslexia present a language profile in the domain of grammatical morphology similar to that of children with SLI.

A comparison between the nominal and verbal domain cannot be done straightforwardly. The children (including the controls) do not seem to have reached the stage where finiteness is obligatory and where the conditions for frequent use of finite lexical verbs are satisfied. On the other hand, in the nominal 
domain, the use of plural forms is near Brown's (1973) acquisition criterion (90\% use in obligatory context) among the controls. Consequently, the finding in previous SLI research that production of correct noun morphology exceeds that of verb morphology cannot be properly tested.

\section{EXPERIMENT 3: CATEGORICAL PERCEPTION OF SPEECH SOUNDS}

There are indications that categorisation of speech sounds in phonemic classes is less consistent in children with (manifest) dyslexia as compared to control children. Dyslexic children's phoneme categorisation is characterised by less sharply defined phoneme boundaries and less steep categorisation functions, as determined with standard categorical perception tasks (Maassen, Groenen, \& Crul, 2001). Such findings imply a speech processing problem in dyslexics. It remains unclear, however, whether this problem is an antecedent or a consequence of the reading difficulty. It has been shown that young children at-risk for familial dyslexia have oral language problems, but data about their early speech perception skills are scarce. An exception is a study by (Richardson, Leppänen, Leiwo, \& Lyytinen, 2003), who found that Finnish at-risk infants need a larger difference in occlusion time than control children in order to be able to discriminate 'atta' from the minimally different 'ata'. We ran a categorical perception experiment, in which children at age 3;6 were exposed to continua spanning the consonantal contrast $(/ \mathrm{p} /-/ \mathrm{k} /)$ as well as vocalic (length $\&$ timbre) contrast /a/-/a:/.

\section{Participants}

31 at-risk children (average age 3;11), 10 children with SLI (4;4), and 26 controls $(3 ; 11)$ took part. Of the 67 children tested, 25 (37\%) failed to complete the task (16 at-risk, 2 SLI, 7 control). The number of children completing one of the two experiments was higher. However, we only present the results of those children that completed both the $/ \mathrm{k} /-/ \mathrm{p} /$ and the $/ \mathrm{a} /-/ \mathrm{a}$ / test.

\section{Materials and Procedure}

Two stimulus series with seven stimuli each were presented to the children. The stimuli constituted a six-step continuum between the $/ \mathrm{p} /$ and $/ \mathrm{k} /$ in the words /pop/ and /kıp/ ('doll' and 'cup') and a six-step continuum between the vowels /a:/ and /a/ in the words /za:k/ and /zak/ ('shop' and 'bag'). The continua were generated by interpolation between the relative amplitudes of the spectral envelopes of the original words, as spoken by an adult male native speaker of Dutch. In the vowel continuum, vowel duration was also manipulated by decreasing it in equal steps of $15 \mathrm{~ms}$.

The participants heard each token 6 times, and had to respond each time by pointing at one of two pictures matching the words that represented the endpoints of the continua. The stimuli were presented via headphones connected to a computer. We expected that meaningful stimuli and simple picture selection would engage children more than the traditionally used nonsense syllables presented as names of e.g. similar toy animals. 


\section{Results and Discussion}

Figure 2 shows the percentage / kıp/ responses of the three subject groups for each of the 7 points on the continuum. The slope of the categorisation functions of the at-risk and the SLI groups are less steep than the function gradient of the control group. The slope is the reciprocal of the standard deviation and indicates the range of uncertainty distinguishing one phoneme category from another. A steep slope indicates a small uncertainty range and suggests a highly consistent ability to categorise a speech contrast, whereas a shallow slope indicates a large range of uncertainty, suggesting difficulties in identifying the speech stimuli. The data also show that the at-risk and SLI children had more difficulty with categorising the (unambiguous) endpoint stimuli, which implies that their phoneme identification was also impaired.

Analysis of variance (repeated measures) was employed to model percent /kəp/ responses as the dependent variable for the seven points on the continuum. All possible interactions between group, stimulus level, and age were considered as potential terms. It appears group, stimulus level, as well as interaction between group and stimulus level contributed significantly $(p<0.01)$ to the model fitting the phoneme categorisation scores. The slope of the categorisation function differed significantly between the control group and both the at-risk and the SLI group. The SLI group was older than the two other groups. However, after controlling for age, the SLI group still performed relatively poorly. The slopes for the three groups, after controlling for age (significant at $p=0.042$ ) were as follows:

- Control: 17.459

- At-risk: 11.091

- SLI: 11.607

\section{Stop-consonant categorisation}

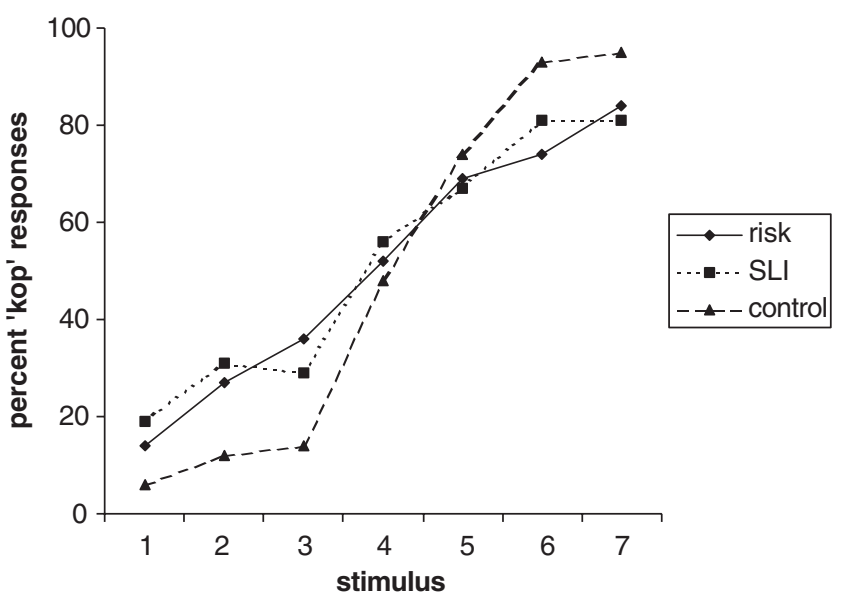

Figure 2. Categorical perception: the mean percentages of $/ \mathrm{k}\lrcorner \mathrm{p} /$ responses in the three groups, for each of the 7 points on the /pop/-/kop/ continuum. 


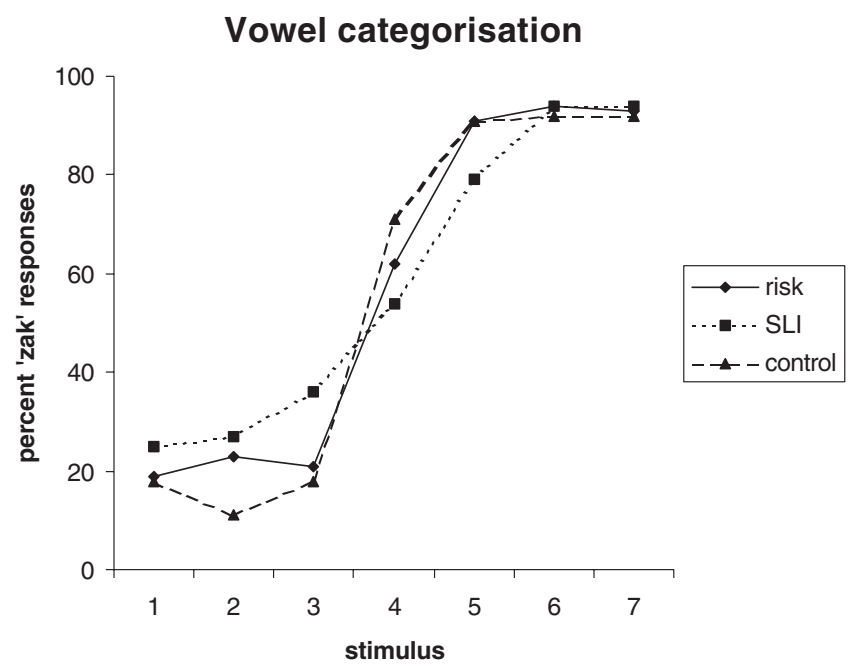

Figure 3. Categorical perception: the mean percentages of /za:k/ responses in the three groups, for each of the 7 points on the /zak/-/za:k/ continuum.

The results of the /za:k/-/zak/ test are presented in Figure 3. The functions indicate that the three groups do not differ in their categorization responses, as was the case with the stop-consonant contrast. A repeated measurement analysis was conducted with percent /za:k/ responses as the dependent variable for each of the seven levels of stimulus. The most economic model adequately predicting the phoneme categorization data only contained the parameter Stimulus.

The conclusion we draw from these results is that children at-risk for dyslexia as a group clearly have less consistent perception of stop consonants (not vowels) than age-matched controls. Their performance resembles the profile observed in children with SLI. This outcome is consistent with Richardson et al.'s (2003) result, and parallels the performance of older, manifest dyslexics. Given the fact that the participants in our study have not been exposed to any formal instruction on orthography, it seems safe to conclude that the speech perception problem observed in older dyslexics cannot be the result of the reading deficiency. Rather, it is likely that a deficient or delayed speech perception/processing skill is a precursor of dyslexia. Such a finding is compatible with various models assuming a causal role for speech perception in the development of dyslexia.

\section{EXPERIMENT 4: PHONOLOGICAL PROCESSING}

Phonological processing, which comprises the perception, storage and reproduction of phonological forms, is often operationalised by means of the non-word repetition task (NRT). NRT performance has been reported to be deficient in language-impaired individuals, as well as in dyslexics and children at-risk for dyslexia (Carroll \& Snowling, 2004; Ellis-Weismer et al., 2000; Gallagher et al., 2000; Goulandris, Snowling, \& Walker, 2000). Generally, it has been found to correlate with reading skills. If we assume that a deficit in phonological processing predates the emergence of manifest dyslexia, we predict that NRT performance in at-risk children - on average-will be worse than in controls. 


\section{Participants}

In the present experiment, 65 at-risk children, 22 children with SLI, and 31 controls (all from the toddler cohort) took part. Seven at-risk children failed to complete this task. The average age of the at-risk children was 4,5 , the SLI children were $4 ; 8$, and the control children $4 ; 6$.

\section{Materials and Procedure}

A non-word repetition test (NRT) was constructed after Dollaghan and Campbell (1998). This NRT minimises the effect of language knowledge and avoids assessing productive phonological abilities rather than phonological processing skills. The test items consisted of two, three, four, and five syllable non-words.

The non-word items were introduced to the children as names of strange creatures, which were depicted in colourful drawings. The non-words were presented one at a time through a CD player and loudspeakers. Every word was introduced by a beep to ensure children's attention. Order of presentation was random with the restriction that the syllable length of two successive non-words was always different. All subjects heard the non-words once. The children's repetitions were recorded on a DAT tape, and were phonetically transcribed afterward.

\section{Results and Discussion}

The performance on the NRT can be expressed in various measures, which usually correlate rather strongly. Here, we only present the percentages of phonemes correctly reproduced (PPC, for a more detailed report, see De Bree, Wilsenach, Gerrits, \& Wijnen, 2003). The averages per group are presented in Figure 4. Visual inspection of these data suggests a clear trend, such that the controls perform best, the SLI children worst, while the at-risk children hold an intermediate position. A repeated measures analysis with Group as between-

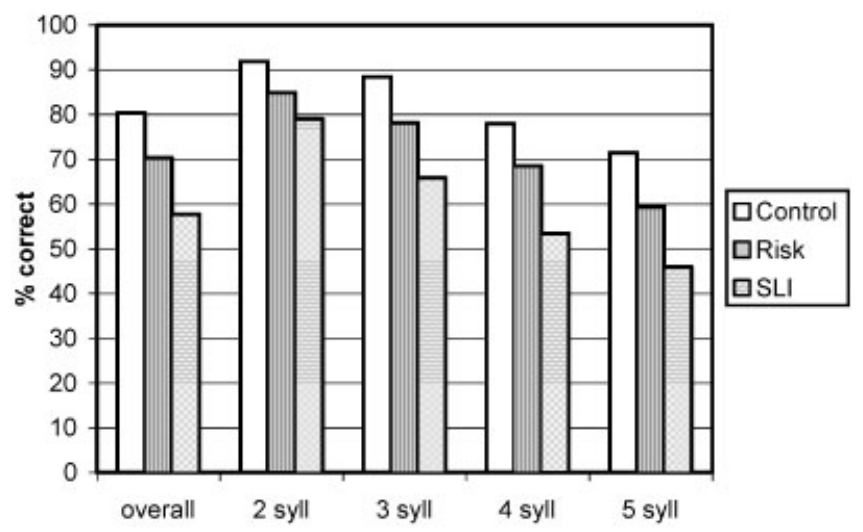

Figure 4. Non-word repetition: average percentages of phonemes repeated correctly by each of the three groups, and broken down over different word lengths $(2,3,4$ and 5 syllables). 
subjects and Phoneme Percentage Correct as within-subjects factor show an interaction between group and PPC $(F)(6,321) 11.00, p<0.001)$. Results are also significant for each main efect, with $\operatorname{PPC}(F(3,321) 82.68, p<0.001)$ and group $(F(1,107) 63.30, p<0.001)$. Post-hoc Tukey HSD analyses showed that all of the pair-wise differences among the conditions were significant at the 0.05 level. This result implies that the at-risk children have difficulty with phonological processing (as expected), i.e. difficulties with phonological segmentation and encoding. These skills are necessary for language-learning and reading acquisition. In this respect they resemble the language-impaired children.

\section{EXPERIMENT 5: MISPRONUNCIATION DETECTION}

A deficit in phonological processing may result in less detailed or incorrect phonological representations of words in the mental lexicon (e.g. Brady, 1997). If this is the case, a phonological deficit in children with dyslexia and SLI would affect the recognition of words in these children. In particular, if the phonological representations of words are not sufficiently specified, a phonological mismatch would be less harmful for the recognition of these words. As a result, children with a phonological deficit would have more difficulty in detecting phonological mispronunciations than children without a phonological deficit. Indeed, Carroll and Snowling (2004) found that in a group of 3-6 year-old children with a risk for dyslexia and speech-delayed children had more difficulty on a mispronunciation detection task than normally developing children. Therefore, we predicted that the at-risk group and the SLI group would be less good in detecting mispronunciations at the beginning of words (resulting in non-existing words) than the control group.

\section{Participants}

In the present experiment, 48 at-risk children (average age 5;1), 18 children with SLI $(5 ; 4)$, and 29 controls $(5 ; 1)$ took part.

\section{Materials and Procedure}

There were two mispronunciation conditions in which the initial phoneme of the target word was mispronounced: a maximal mismatch condition and a minimal mismatch condition. Items in the maximal mismatch condition differed from the target words in place of articulation, manner and voicing of the initial phoneme (plosive of fricative), so for example pebra was substitute for zebra, or saby for baby. In the minimal mismatch condition experimental items differed from the target words only in place of articulation of the initial phoneme (plosive of fricative), so that zebra would be replaced by vebra, or baby by daby. There were 12 target words ( 6 with an plosive and 6 with a fricative). All words were bisyllabic with a strongweak stress pattern. Each word appeared in the two mispronunciation conditions, as well as in the correct form, resulting in 36 items. In addition, there were 12 filler words, which were pronounced correctly. Thus, in all we had 48 items, half of which were produced correctly and half incorrectly. The items were presented in random order. 
Children were told that they were going to teach the computer to speak. First, the computer had to learn the words. Therefore, the child had to name pictures that appeared on the screen. In this way the child was familiarised with the pictures and it was ascertained that the child knew the names of the objects presented. Subsequently, the children saw the same pictures again, but this time the computer 'named' the pictures. The participants' task was to push a big red button when a word was pronounced incorrectly. Before the real test session started, there was a training session consisting of two correctly and two incorrectly pronounced words.

\section{Results and Discussion}

Figure 5 shows the mean percentage correct made by each of the subject groups, plotted separately for the two mispronunciation conditions. The control children detected more phonological mismatches correctly than the at-risk children, and the percentage of correct detections was lower still in the SLI group (98.8, 94.6 and $84.5 \%$, respectively). This was confirmed by a repeated measures ANOVA with mispronunciation condition as a within-subject factor and subject group as a between-subject factor. There was a main effect of group $(F(2,92)=11.67$, $p<0.0001$, and a post hoc Tukey HSD test showed that all pair-wise differences among the three groups were significant at the 0.05 level. Furthermore, the ANOVA showed a significant effect of mispronunciation condition $(F(1,92)=22.54, p<0.0001)$. More correct detections were made in the maximal mismatch condition $(95.0 \%)$ than in the minimal mismatch condition $(90.0 \%)$. Furthermore, there was a significant interaction between mispronunciation condition and group $(F(2,92)=5.32, p<0.01)$. A Tukey HSD test indicated that this interaction was due to the fact that in the maximal mismatch condition only the SLI group differed significantly from the at-risk and control groups, while in the minimal mismatch condition all pair-wise differences among the three groups were significant.

These findings indicate that the children at-risk for dyslexia and the children with SLI have more difficulty detecting small phonological mismatches than

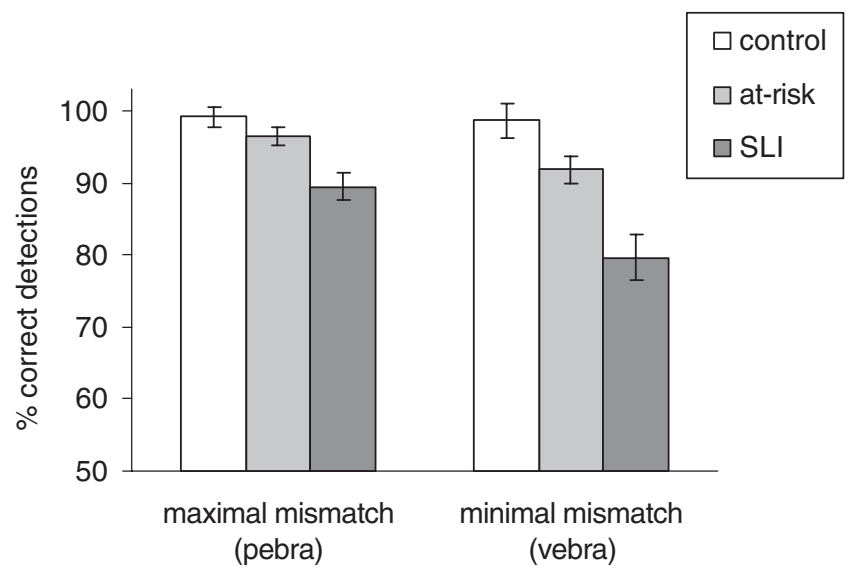

Figure 5. Percentage of correct detections (misses) in the mispronunciation detection task (vertical bars present two standard errors). 
control children. This may be the result of insufficiently specified phonological representations of words in the former two groups. However, it is also possible that these results reflect a problem at a lower level of processing. Although it is difficult to determine the locus of the effect, it seems that the poorer performance of both the children at-risk for dyslexia and the children with SLI is a result of a phonological deficit.

\section{EXPERIMENT 6: RHYME DETECTION}

Much work has stressed the role of phonological awareness in the aetiology of dyslexia. This is backed up by data showing that children who have a difficulty in learning to read and spell in many cases also fail on tasks requiring explicit phonological analysis (Adams, 1991; Goswami \& Bryant, 1990; Perfetti, Beck, Bell, \& Hughes, 1987). Recognising rhyme is one such metaphonological ability, as it entails the capacity to segment syllables into constituents (onset, rime) and compare these. The ability to rhyme has been estimated to develop around age four (Menn \& Stoel-Gammon, 1995) and is claimed to be a predictor of reading comprehension skills (Bird, Bishop, \& Freeman, 1995; Brady, 1997). Our odd-one out task aimed to establish whether at-risk children and controls differ in rhyme detection ability, and, if so, whether at-risk children's performance resembles that of children with SLI.

\section{Participants}

In this experiment 56 at-risk children, 22 children with SLI, and 24 control children (from the toddler cohort) took part. One child in the control group, 5 atrisk children and 2 children with SLI were unable to complete the task, apparently as a result of a lack of rhyming abilities and/or discrimination skills. The average age of the at-risk and control group was 5;1, that of the SLI group 5;4.

\section{Materials and Procedure}

Ten series of four monosyllabic existing words of Dutch were formed, such that one of the four differed from the other three with the entire rime (e.g. zwaard [zwa:rt] - paard [pa:rt] - taart [ta:rt]—bloem [blum]). The words were controlled for acquisition age. The four-word series were pronounced by the experimenter, more than once if necessary, and matching pictures were presented to help the children remember the series. Participants were instructed to select the word (picture) that did not rhyme with the others. The ten test trials were preceded by 2 practice trials.

\section{Results and Discussion}

Correct and incorrect responses were scored during the experiment. The overall mean proportions of correct responses per group are displayed in Figure 6. The bar graph indicates that the SLI children performed worst, the controls best, and the at-risk children take a middle position. 


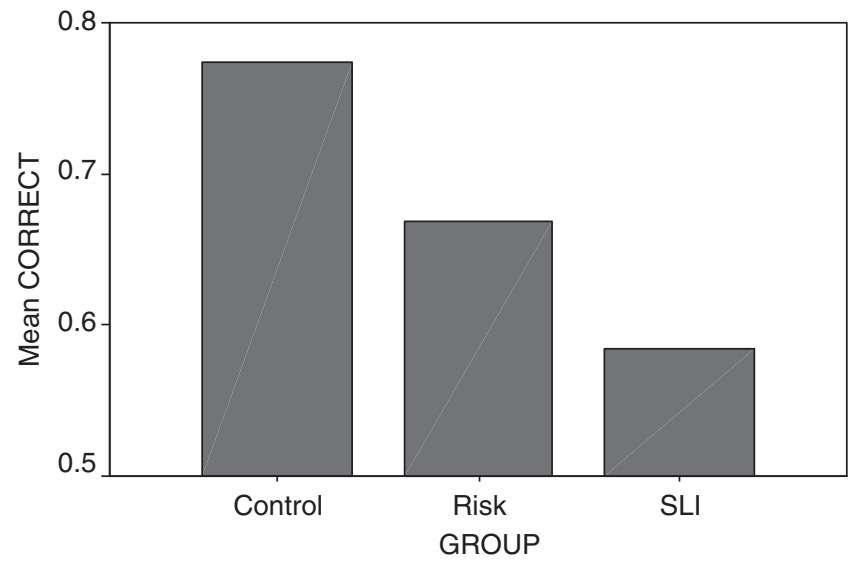

Figure 6. Rhyme detection: average proportion correct detection of the odd one out, in the three groups of participants.

A one-way ANOVA shows that the differences between groups are statistically significant $(F(2,83)=3.569, p=0.033)$. Tukey HSD post hoc tests established that the differences between the control and at-risk group, and between the control and SLI group were significant ( $p$ values 0.006 and 0.048 , respectively). The difference between the at-risk and SLI group failed to reach significance. The results confirm our expectation that children at-risk for dyslexia have more difficulties on a rhyme task than the control group. This implies that metaphonological skills are less well developed in this population than can be expected on the basis of age. The same is true for the SLI children.

\section{GENERAL DISCUSSION}

The goal of the longitudinal research project reported on here is to trace the primary language development of children at-risk for dyslexia, and to determine whether this deviates, quantitatively or qualitatively, from the typical pattern observed in children without a genetic risk. Children with specific language impairment were included in the comparison for two reasons. First, SLI can be viewed as a yardstick of deviant language development; it provides insight in the components of linguistic skill that are particularly vulnerable, and in the way they are affected by a developmental problem. Secondly, various hypotheses suggest an aetiological link between SLI and dyslexia, which would entail a close similarity of the language symptoms in individuals assigned to either of the two categories. This similarity is under review here.

Our results indicate that children at-risk for dyslexia as a group display a systematic and consistent developmental language delay. The quantitative measures we obtained from the at-risk group are generally intermediate between those of the control children and the children with SLI. With regard to grammar, we observed the following: (1) At the early age of 19 months, at-risk children cannot discriminate between grammatical and ungrammatical sentences, whereas control children of the same age can. Six months later, the at-risk 
children have not yet caught up with their peers. This finding suggests that children at-risk for dyslexia have considerable problems in discovering the grammatical structure of their native language, which may impact on and be reflected in language production. (2) In elicited language production, the at-risk children (around age 3;6) display a command of grammatical morphology typical of younger normally developing children. Quantitatively (i.e. in the number of errors) their performance approaches that of the SLI children. However, qualitatively, there are some subtle yet interesting difference between at-risk children and their age peers with SLI, which warrant further analyses.

In the domain of phonetics and phonology, we have seen that (3) the categorical perception of stop consonants in at-risk children around age 4 is significantly less clear-cut than in the control group, and in fact not distinguishably better than in children with SLI. This is suggestive of a speech recognition problem. (4) At age 4;6, at-risk children perform poorly on a nonword repetition task compared to the control group, but better than the SLI children, indicating that at-risk children's phonological processing capacity is reduced. (5) At age 5, at-risk children make significantly more mistakes than controls in detecting phonemic mispronunciations, particularly when the substituting segment is phonologically close to the target. Children with SLI make even more errors. Apparently, at-risk as well as SLI children sustain deficits in the analysis and/or representation of phonological word forms in different degrees. (6) The at-risk children display a marked delay in phonological awareness at age 5, as measured with a rhyme detection task. This is an indication that a capacity widely seen as a precondition for the smooth acquisition of orthographic skills is underdeveloped.

The differences between at-risk children and controls observed here replicate some of the findings of earlier prospective studies. Notably, our data confirm the observations by Locke et al. (1997) and Pennington and Lefly (2001) that children at-risk for dyslexia are deficient in processing and representing speech sounds, as well as in the ability to deliberately judge and manipulate phonological form. Moreover, in line with the results of Lyytinen et al. (2001) and Scarborourgh (1990), we see a delay in the use of grammatical morphology. Our results suggest that this is foreshadowed by a decreased sensitivity to grammatical patterns in the input language at an early age. Importantly, the present results indicate that the language problems putatively anticipating dyslexia go beyond the wellattested literacy-related metaphonological skills.

A question that arises is whether the various deficits found in the at-risk children stem from a condition that impacts on speech processing, phonology and grammar separately, or whether it is one component that carries the primary dysfunction, with a 'cascading' effect throughout the entire language system. An example of a general deficit impacting on each of the language modules directly might be a reduced working memory capacity (Gathercole \& Baddeley, 1989). An example of a 'cascade model' is one in which the primary problem is located in speech perception (Mody, Studdert-Kennedy, \& Brady, 1997; Studdert-Kennedy, 2002), or phonological processing (Snowling, 2001). The consequence of this might be that word form representations are insufficiently specified. In turn, this may have detrimental consequences for the extraction and representation of morphological and grammatical regularities. The results presented here, showing differences between groups, are compatible with both types of hypotheses. 
Specific contrastive tests would require detailed analyses of individual children's linguistic profiles, to determine, for example, whether deficits at various levels can occur independently. The results of these analyses are pending.

The language profile presented by the at-risk children seems to put them approximately halfway a continuum with control children at the high end and children with SLI at the low end. Our results corroborate findings reported earlier (Bishop \& Adams, 1990; Catts, 1993) that children at-risk for dyslexia resemble children with a manifest developmental language delay. Could this mean that SLI and dyslexia are basically the same disorder, differing only in degree? It should be emphasised here that the resemblance between the groups reported here is largely quantitative, not qualitative. The exception concerns the production of grammatical morphology, where a subtle difference between the at-risk and SLI group is found. Obtaining a better grasp of the (dis)continuity between SLI and dyslexia demands more qualitative analyses, as well as a detailed exploration of the patterns of correlations among the various quantitative data we obtained. We are currently working on both types of analyses, attempting to pinpoint the language acquisition differences between the two syndromes. We expect this will be helpful in deciding between various models of pathogenesis.

Apart from performing qualitative and more fine-grained analyses, it is clear that it is highly relevant to the continuity issue to determine which of our at-risk children actually become dyslexics. For a (strong version of) the continuity hypothesis to hold, we should find a biconditional relation between developmental language delays and reading problems. In other words, we should see that the at-risk children with language problems will be the ones displaying difficulties with reading acquisition. Short of such a relation, i.e. reading failures in the absence of language problems, or vice versa, the similarity between at-risk children and children with SLI regarding language development would have to be explained by recourse to more general mechanisms. This would perhaps be more consistent with a clinical perspective. After all, dyslexia and SLI are considered to be clinically distinguishable. Nonetheless, particular phenomena in language development may still turn out to be reliable and clinically relevant early precursors of developmental dyslexia.

\section{ACKNOWLEDGEMENTS}

The research reported was made possible by a grant from the Netherlands Organisation for Scientific Research (NWO, No. 360-70-030), and substantial financial and technical support from the Utrecht institute of Linguistics OTS at Utrecht University. We would like to thank all the parents and children who participated in the project. Furthermore, we thank two anonymous Dyslexia reviewers for their constructive commentary on a previous version of this paper.

\section{References}

Adams, M. J. (1991). Beginning to read. Cambridge, MA: The MIT Press.

Bird, J., Bishop, D., \& Freeman, N. (1995). Phonological awareness and literacy development in children with expressive phonological impairments. Journal of Speech and Hearing Research, 38, 446-462. 
Bishop, D. V. M. (1994). Grammatical errors in specific language impairment: Competence or performance limitations. Applied Psycholinguistics, 15, 507-550.

Bishop, D. V. M. (1997). Pre- and perinatal hazards and family background in children with specific language impairments: A study of twins. Brain and Language, 56, 1-26.

Bishop, D. V. M., \& Adams, C. (1990). A prospective study of the relationship between specific language impairment, phonological disorders and reading retardation. Journal of Child Psychology and Psychiatry, 21, 1027-1050.

Brady, S. (1997). Abilities to encode phonological representations: An underlying difficulty of poor readers. In B. Blachman (Ed.), Foundations of reading acquisition and dyslexia:

Implications for early intervention. London etc: Lawrence Erlbaum.

Brown, R. (1973). A first language: The early stages. Cambridge, MA: Harvard University Press.

Brus, B. T., \& Voeten, M. J. M. (1973). Een-Minuut-Test [One Minute Test]. Nijmegen: Berkhout.

Byrne, B., Fielding-Barnsley, R., Ashley, L., \& Larsen, K. P. (1997). Assessing the child's and the environment's contribution to reading acquisition-what we know and what we don't know. In B. Blachman (Ed.), Foundations of reading acquisition and dyslexia: Implications for early intervention (pp. 265-285). Mahwah, NJ: Lawrence Erlbaum.

Carroll, J. M., \& Snowling, M. J. (2004). Language and phonological skills in children at high risk of reading difficulties. Journal of Child Psychology and Psychiatry, 45(3), 631-640.

Catts, H. W. (1993). The relationship between speech-language impairments and reading disabilities. Journal of Speech and Hearing Research, 36(5), 948-958.

Catts, H. W., Fey, M. E., Zhang, Y., \& Tomblin, J. B. (2001). Estimating the risk of future reading difficulties in kindergarten children: A research-based model and its clinical implementation. Language, Speech and Hearing Services in Schools, 32(1), 38-50.

Catts, H. W., \& Kamhi, A. G. (Eds.). (1999). Language and reading disabilities. Needham Heights, MA: Allyn \& Bacon.

De Bree, E., Wilsenach, C., Gerrits, E., \& Wijnen, F. (2003). In search for precursors of dyslexia: Phonological processing and working memory in children at risk for dyslexia and children with SLI. Paper presented at the Child Phonology Conference, July 1-4, The University of British Columbia, Vancouver, BC, Canada.

Dollaghan, C., \& Campbell, T. F. (1998). Nonword repetition and child language impairment. Journal of Speech, Language and Hearing Research, 41, 1136-1146.

Ellis-Weismer, E., Tomblin, J. B., Zhang, X., Buckwalter, P., Chynoweth, J. G., \& Jones, A. (2000). Nonword repetition performance in school-age children with and without language impairment. Journal of Speech, Language and Hearing Research, 43, 865-878.

Fletcher, P., \& Ingham, R. (1995). Grammatical impairment. In P. Fletcher \& B. MacWhinney (Eds.). The handbook of child language. Oxford: Blackwell.

Gallagher, A., Frith, U., \& Snowling, M. J. (2000). Precursors of literacy delay among children at genetic risk of dyslexia. Journal of Child Psychology and Psychiatry, 41(2), 203-213.

Gathercole, S., \& Baddeley, A. D. (1989). Evaluation of the role of phonological STM in the development of vocabulary in children: A longitudinal study. Journal of Memory and Language, 28, 200-213.

Goswami, U., \& Bryant, P. (1990). Phonological skills and learning to read. Hove: Lawrence Erlbaum.

Goulandris, N. K., Snowling, M. J., \& Walker, I. (2000). Is dyslexia a form of specific language impairment? A comparison of dyslexic and language impaired children as adolescents. Annals of Dyslexia, 50, 103-120.

Grigorenko, E. L. (2001). Developmental dyslexia: An update on genes, brains and environments. Journal of Child Psychiatry and Psychology, 42, 91-125.

Höhle, B., \& Weissenborn, J. (2003). German-learning infants' ability to detect unstressed closed-class elements in continuous speech. Developmental Science, 6(2), 122-127. 
Kamhi, A. G., \& Catts, H. W. (1986). Toward an understanding of developmental language and reading disorders. Journal of Speech and Hearing Disorders, 5, 337-347.

Kirk, S., McCarthy, J., \& Kirk, W. (1968). The Illinois test of psycholinguistic abilities. Urbana, IL: University of Illinois Press.

Koster, C., Been, P. H., Koster, F., Diepstra, H. D., van Leeuwen, T. H., \& Krikhaar, E. (2004). Productive lexical acquisition in infants at risk for dyslexia and typically developing infants. Paper presented at the Sixth BDA International conference. Warwick, 27-30 March 2004.

Lefly, D. L., \& Pennington, B. F. (1996). Longitudinal study of children at high family risk for dyslexia: The first two years. In M. L. Rice (Ed.), Towards a genetics of language (pp. 49-75). Hillsdale, NJ: Lawrence Erlbaum.

Leonard, L. B. (1998). Children with specific language impairment. Cambridge, MA: MIT Press. Locke, J. L., Hodgson, J., Macaruso, P., Roberts, J., Lambrecht-Smith, S., \& Guttentag, C. (1997). The development of developmental dyslexia. In C. Hulme \& M. J. Snowling (Eds.), Dyslexia: Biology, cognition and intervention (pp. 72-96). London: Whurr.

Lyytinen, P., Poikkeus, A. M., Laakso, M. L., Eklund, K., \& Lyytinen, H. (2001). Language development and symbolic play in children with and without familial risk for dyslexia. Journal of Speech, Language and Hearing Research, 44, 873-885.

Maassen, B., Groenen, P., \& Crul, T. (2001). Identification and discrimination of voicing and place-of-articulation in developmental dyslexia. Clinical Linguistics and Phonetics, 15, 319-339.

MacArthur, G. M., Hogben, J. H., Edwards, V. T., Heath, S. M., \& Mengler, E. D. (2000). On the 'specifics' of specific reading disability and specific language impairment. Journal of Child Psychology and Psychiatry, 41, 869-874.

Menn, L., \& Stoel-Gammon, C. (1995). Phonological development. In P. Fletcher \& B. MacWhinney (Eds.). The handbook of child language. Oxford: Blackwell.

Mody, M., Studdert-Kennedy, M., \& Brady, S. (1997). Speech perception deficits in poor readers: Auditory processing or phonological coding? Journal of Experimental Child Psychology, 64, 199-231.

Oetting, J., \& Rice, M. L. (1993). Morphological deficits of children with SLI:

Evaluation of number marking and agreement. Journal of Speech and Hearing Research, 36, 1249-1257.

Paul, R. (2000). Predicting outcomes of early expressive language delay: Ethical implications. In D. V. M. Bishop \& L. B. Leonard (Eds.), Speech and language impairments in children: Causes, characteristics, intervention and outcome. Hove: Psychology Press.

Pennington, B. F., \& Lefly, D. L. (2001). Early reading development in children at family risk for dyslexia. Child Development, 72(3), 816-833.

Perfetti, C. A., Beck, I. L., Bell, L. C., \& Hughes, C. (1987). Phonemic knowledge and learning to read are reciprocal: A longitudinal study of first grade children. Merrill-Palmer Quarterly, 33, 283-319.

Richardson, U., Leppänen, P. H. T., Leiwo, M., \& Lyytinen, H. (2003). Speech perception of infants with high familial risk for dyslexia differs at the age of 6 months. Developmental Neuropsychology, 23, 385-397.

Santelmann, L., \& Jusczyk, P. (1998). Sensitivity to discontinuous dependencies in language learners: Evidence for processing limitations. Cognition, 69, 105-134.

Scarborough, H. S. (1990). Very early language deficits in dyslexic children. Child Development, 61, 1728-1734.

Scarborough, H. S. (1991). Antecedents to reading disability: Preschool language development and literacy experiences of children from dyslexic families. Reading and Writing: An Interdisciplinary Journal, 3, 219-233.

Snijders, J. T., Tellegen, P. J., \& Laros, J. A. (1988). Snijders-Oomen niet-verbale intelligentietest $S O N-R$ 5.5-17. Verantwoording en handleiding. Groningen: Wolters-Noordhoff. 
Snowling, M. J. (2001). From language to reading and dyslexia. Dyslexia, 7, 37-46.

Studdert-Kennedy, M. (2002). Deficits in phoneme awareness do not arise from failures in rapid auditory processing. Reading and Writing: An Interdisciplinary Journal, 15, 5-14.

Tomblin, J. B. (1989). The effects of birth order on the occurrence of development language impairment. British Journal of Disorders of Communication, 25, 77-84.

Van den Bos, K. P., Lutje Spelberg, H. C., Scheepstra, A. J. M., \& de Vries, J. R. (1994).

De Klepel, een test voor de leesvaardigheid van pseudowoorden. Verantwoording, handleiding, diagnostiek en behandeling. Nijmegen: Berkhout.

Wijnen, F., \& Verrips, M. (1998). The acquisition of Dutch syntax. In S. Gillis \&

A. De Houwer (Eds.), The acquisition of Dutch (pp. 223-299). Amsterdam: John Benjamins. 